\title{
Association between predominantly plant-based diets and iron status in Chinese adults: a cross-sectional analysis
}

\author{
Jingjing He, Xin Shen, Aiping Fang, Jie Song, He Li, Meihan Guo and Keji Li* \\ Department of Nutrition and Food Hygiene, School of Public Health, Peking University, No. 38 Xueyuan Road, \\ Haidian District, Beijing 100191, People's Republic of China
}

(Submitted 3 May 2016 - Final revision received 28 August 2016 - Accepted 16 September 2016)

\begin{abstract}
Current evidence of the relationship between diets and Fe status is mostly derived from studies in developed countries with Western diets, which may not be translatable to Chinese with a predominantly plant-based diet. We extracted data that were nationally sampled from the 2009 wave of China Health and Nutrition Survey; dietary information was collected using 24-h recalls combined with a food inventory for 3 consecutive days. Blood samples were collected to quantify Fe status, and log-ferritin, transferrin receptor and $\mathrm{Hb}$ were used as Fe status indicators. In total, 2905 (1360 males and 1545 females) adults aged 18-50 years were included for multiple linear regression and stratified analyses. The rates of Fe deficiency and Fe-deficiency anaemia were 1.6 and $0.7 \%$ for males and 28.4 and $10.7 \%$ for females, respectively. As red meat and haem Fe consumption differed about fifteen to twenty times throughout the five groups, divided by quintiles of animal protein intake per $4.2 \mathrm{MJ} / \mathrm{d}$, only Fe status as indicated by log-ferritin $(P=0.019)$ and transferrin receptor $(P=0.024)$ concentrations in males was shown to be higher as intakes of animal foods increased. Log-ferritin was positively associated with intakes of red meat $(B=0 \cdot 3 \%, P=0 \cdot 01)$ and haem Fe $(B=12.3 \%, P=0 \cdot 010)$ in males and with intake of non-haem Fe in females $(B=2 \cdot 2 \%, P=0 \cdot 024)$. We conclude that diet has a very limited association with Fe status in Chinese adults consuming a traditional Chinese diet, and a predominantly plant-based diet may not be necessarily responsible for poor Fe status.
\end{abstract}

Key words: Iron-deficiency anaemia: Predominantly plant-based diets: Haem iron: Ferritin

Anaemia affects 1.62 billion of the world's population, half of which are assumed to be due to Fe deficiency (ID) according to WHO reports ${ }^{(1)}$. ID affects all ethnic groups without exception $^{(2,3)}$, and its overall prevalence is about $50 \%$ in developing countries and may reach $10 \%$ or more in developed countries $^{(2)}$. ID occurs in sequentially developing stages, and the severest stage is Fe-deficiency anaemia (IDA). ID and IDA have many adverse functional consequences and socio-economic implications - for example, decreased cognitive performance, impaired physical capacity and work performance, increased morbidity from infections, and increased costs incurred by therapeutic measures ${ }^{(4)}$. Besides physiological (e.g. menstrual losses, repeated pregnancies) and pathological (e.g. tumours, parasitic infestations) factors ${ }^{(3)}$, insufficient Fe intake and/or low bioavailability are thought to be the main causes of ID ${ }^{(5)}$.

$\mathrm{Fe}$ is present in foods as haem or non-haem Fe. In most animal foods (such as livestock meat, poultry, fish flesh and offal), about $40 \%$ of the $\mathrm{Fe}$ is haem $\mathrm{Fe}^{(6-8)}$, the absorption of which is more efficient (approximately $15-35 \%)^{(3,9)}$ and can be enhanced by unidentified factors in meat, poultry and fish themselves ${ }^{(10,11)}$. However, in plant foods, all the $\mathrm{Fe}$ is non-haem Fe, the bioavailability of which is lower (approximately $2-20 \%)^{(3,9)}$, whereas some constituents (e.g. ascorbic acid and possibly of carotene) contained in plant foods can enhance and other constituents (e.g. tannins, polyphenols, phytic acid and soya protein) can inhibit the absorption of nonhaem $\mathrm{Fe}^{(7,12-14)}$. When consumed concurrently in the same meal, some other dietary factors can substantially enhance (e.g. livestock meat, poultry, fish and alcohol) or inhibit (e.g. eggs and $\mathrm{Ca}$ ) non-haem Fe absorption, whereas haem Fe is less influenced $^{(7,12,13)}$.

A number of cross-sectional studies in developed countries have investigated the associations between dietary factors and Fe status. Although many studies have observed that increased meat intake ${ }^{(15-17)}$ and haem Fe intake ${ }^{(18-20)}$ are associated with better Fe status (often measured by serum ferritin and $\mathrm{Hb}$ ), a few studies, however, have found no association between meat or haem Fe intake and Fe status ${ }^{(21-23)}$. As for other dietary factors (e.g. total $\mathrm{Fe}, \mathrm{Ca}$, ascorbic acid, fruits, vegetables, dairy products, tea, coffee and alcohol) and lifestyle factors (e.g. smoking), the results of correlation analysis between Fe status and these factors have been somewhat inconsistent ${ }^{(21,24,25)}$.

\footnotetext{
Abbreviations: CHNS, China Health and Nutrition Survey; ID, iron deficiency; IDA, iron-deficiency anaemia; PAL, physical activity level.
} 
These enhancers and inhibitors, mostly identified from singlemeal Fe absorption tests, do not always have an impact on Fe status. Studies measured over complex meals or longer periods have challenged the practical impact of single-meal studies, which may not reflect the actual Fe bioavailability of daily diet and the effects of enhancers and inhibitors ${ }^{(26-28)}$. Some studies have proved that body $\mathrm{Fe}$ status is also one of the determinants of dietary Fe absorption and shows an inverse relationship with both haem and non-haem Fe absorptions, and non-haem Fe absorption seems to be more responsive ${ }^{(29-32)}$. When Fe stores are low, non-haem Fe absorption is nearly as efficient as haem Fe, and when Fe stores are high it can be more completely limited ${ }^{(7,29,33)}$.

The above discoveries were mainly derived from studies based on populations or individuals in developed countries. However, dietary patterns have been identified to be largely different between developed and developing countries ${ }^{(34,35)}$. Populations of most developed countries (mainly in Europe and North America) follow a Western diet, which is characterised by higher intakes of processed meat, red meat (i.e. livestock meat), butter, high-fat dairy products, eggs and refined grains ${ }^{(34,35)}$. However, in developing countries such as China, most people adhere to a predominantly plant-based diet, containing higher quantities of grains, legumes, vegetables and fruits and lower quantities of animal foods ${ }^{(34,35)}$. In 2005 , the consumption of livestock products was about $82 \cdot 1$ and $30.9 \mathrm{~kg} /$ person per year in developed and developing countries, respectively, according to FAO reports ${ }^{(36)}$. In view of this difference, it should be questioned whether these findings on dietary and lifestyle factors related to Fe status from developed countries hold in populations of China and other developing countries as well.

Accordingly, using data from the China Health and Nutrition Survey $(\mathrm{CHNS})^{(37)}$, a nationally sampled population in China, this study aimed to determine the prevalence rates of ID and IDA in Chinese adults, and to investigate the associations between dietary, lifestyle and demographic factors and Fe status in males $v$. females aged $18-50$ years, the least and most vulnerable populations to ID, respectively ${ }^{(1,4)}$, who consume a traditional Chinese and predominantly plant-based diet.

\section{Methods}

\section{Study population}

We extracted data from the CHNS, a multipurpose, longitudinal survey in China designed to examine how the social and economic transformation has affected a wide array of nutrition and health-related outcomes ${ }^{(37,38)}$. From 1989 to 2011, a total of nine rounds of the CHNS have covered twelve provinces that vary in geography, demography, economic development and public resources ${ }^{(38)}$. A multistage, random cluster approach was used to draw the sample surveyed in each of the provinces. All participants provided their written informed consent.

In 2009, a total of 8641 adults (aged 18-99 years) had their blood samples collected and assessed as part of the CHNS. Participants were excluded from analyses if they had missing information (Fe status, dietary data, demographic data), had an infection (defined by high-sensitivity C-reactive protein $(\mathrm{CRP}) \geq 3 \mathrm{mg} / \mathrm{l}^{(39)}$ ) or abnormal Fe metabolism. Participants with a history of diseases including diabetes, hypertension, myocardial infarction, stroke, asthma, goitre, and angular cheilosis were excluded. In addition, participants were excluded if they were blind, had physical disabilities, or were pregnant or lactating. On the basis of dietary and biomarker information, participants were further excluded if they had abnormal energy intakes $(<2929$ or $>20920 \mathrm{~kJ} / \mathrm{d})$, excessive total $\mathrm{Fe}$ intakes $(>60 \mathrm{mg} / \mathrm{d}$ ) or abnormal Fe status readings (serum ferritin $>1000 \mathrm{ng} / \mathrm{l}, \mathrm{Hb}<80$ or $>200 \mathrm{~g} / \mathrm{l}$, transferrin $<1.2$ or $>4.6 \mathrm{~g} / \mathrm{l}$, transferrin receptor $>3.7 \mathrm{mg} / \mathrm{l}$ ). Therefore, a sample of 5379 subjects was used to calculate the prevalence of anaemia, ID and IDA. Next, a sample of 4827 subjects (aged 18-94 years) was used for the analysis after excluding participants with moderate and severe anaemia (defined by $\left.\mathrm{Hb}<100 \mathrm{~g} / \mathrm{l}^{(40,41)}\right)$ and those being anaemic but with normal $\mathrm{Fe}$ storage (i.e. $\mathrm{Hb}<130 \mathrm{~g} / \mathrm{l}$ but ferritin $\geq 15 \mathrm{ng} / \mathrm{ml}$ for males and $\mathrm{Hb}<120 \mathrm{~g} / \mathrm{l}$ but ferritin $\geq 15 \mathrm{ng} / \mathrm{ml}$ for females $\left.{ }^{(4)}\right)$. For the regression and stratified analyses, participants aged $>50$ years were excluded, leading to a sample size of 2905 participants (aged 18-50 years).

\section{Assessment of dietary intake}

The measurement of dietary intake in CHNS is a combination of two parts: an individual-level three consecutive 24-h dietary recalls and a household-level food inventory weighing performed over the same $3 \mathrm{~d}$ ( 2 weekdays and 1 weekend day), which were randomly allocated from Monday to Sunday ${ }^{(42)}$.

The three consecutive 24-h dietary recalls were administered by asking individuals to report all the foods consumed away from home each day, and the same daily interview was used to collect at-home individual consumption ${ }^{(42)}$. Some important instructions were provided for interviewers to promote the completeness of the recalls: (a) before the survey, interviewers were required to be acquainted with the containers and food information in the family or region surveyed; (b) during the survey, for each day, enquiries were to be in accordance with mealtime order; (c) for each meal, enquiries were to be conducted following a certain food order (staple food, non-staple food, beverages, fruits and other types of food) to help respondents in recalling; (d) to remind respondents the foods easily overlooked, such as snacks between meals; (e) to remind about foods consumed away from home; and (f) the threedimensional food models or two-dimensional photographs were recommended for food weight estimation ${ }^{(43)}$

Household food consumption was determined by examining changes in food inventory from the beginning to the end of each day, in combination with a weighing and measuring technique. All foods and condiments in home inventory, purchased from markets, picked from gardens and food waste were weighed and recorded. At the end of the survey, all remaining foods were again weighed and recorded. Individual average daily dietary intake was calculated from the household consumption according to the number of meals and days ${ }^{(42,44)}$.

The collection of both household and individual dietary intakes made it possible to check the quality of data collection by comparing the two and by correcting for errors. Thus, each individual's average daily dietary intake, calculated from the 
household survey, was compared with his or her dietary intake on the basis of 24-h recall data. Where significant discrepancies were found, the household and the individual in question were revisited and asked about their food consumption to resolve these discrepancies. All field workers were trained nutritionists who were professionally engaged in nutrition work in their own counties and had participated in other national surveys. Almost all interviewers were graduates of post-secondary schools; many of them had 4-year degrees. In addition, $3 \mathrm{~d}$ of specific training in collection of dietary data was provided for this survey ${ }^{(42)}$.

We combined the individual dietary recall data and the corresponding condiments data (mainly includes edible oil, sauces, vinegar, etc.) of the household food inventory to calculate the total dietary intake. The latest 2002 and 2004 Food Composition Table for China ${ }^{(45,46)}$ was utilised to calculate nutrient values for the dietary data in the present study. Haem Fe was estimated using the assumption that $40 \% \mathrm{Fe}$ is present in animal products including livestock meat, poultry, offal and fish ${ }^{(6-8)}$. The average daily intake of the 3 consecutive days was used for each individual.

The dietary factors in our analysis included nutrient variables, food group variables, and tea, coffee and alcohol consumption. The nutrient variables including total energy, animal protein (i.e. protein of livestock meat, poultry, fish flesh, offal, dairy products and eggs), plant protein, diet fibre, retinol equivalent, vitamin $\mathrm{B}_{12}$, folate, ascorbic acid, $\mathrm{Ca}, \mathrm{Mg}, \mathrm{Zn}, \mathrm{Cu}$, total Fe, haem $\mathrm{Fe}$ and non-haem $\mathrm{Fe}$ were selected from previous studies reporting possible relations with $\mathrm{Fe}$ status for our research interests. The food groups including cereals, potatoes, miscellaneous beans (including adzuki beans, mung beans, kidney beans, broad beans, etc.), vegetables, fruits, red meat (i.e. livestock meat), poultry, fish, dairy foods, eggs, soyabeans, and nuts and seeds were based on the latest 2007 Chinese Dietary Guidelines $^{(47)}$. White meat was defined as the sum of poultry and fish flesh. Tea, coffee and alcohol intakes were all used as dichotomous variables $(1=$ yes, $0=$ no).

The procedures for calculating the total weight of a certain food group are as follows, with soyabean group as an example. First, convert the weights of all foods (e.g. soyabeans, black beans, tofu and soya milk) in the food group (i.e. soyabean group) to raw weights of their edible parts. Second, select a representative food (e.g. soyabeans) from the group and a representative nutrient (e.g. protein) for the chosen kind of food. Third, convert the weight of each food obtained from the first step to equivalent weight of soyabeans according to the ratio of the protein content of that food and soyabeans. Finally, the sum of the equivalent weights of all foods in this group was considered the total weight of the food group.

In order to control for energy intakes, all individual daily nutrient and food data, divided by individual daily total energy, were converted into nutrient density or food density in $\mathrm{g} / 4.2 \mathrm{MJ}$ per $\mathrm{d}$ (equivalent to $\mathrm{g} / 1000 \mathrm{kcal}$ per $\mathrm{d}$ ) or $\mathrm{mg} / 4 \cdot 2 \mathrm{MJ}$ per $\mathrm{d}$ or $\mu \mathrm{g} / 4 \cdot 2 \mathrm{MJ}$ per $\mathrm{d}$.

\section{Assessment of iron status}

Participants who signed informed consent for blood sampling provided samples. After an overnight fast (at least $8 \mathrm{~h}$ ), blood was drawn from an antecubital vein in the morning by trained phlebotomists using the standard protocol. Plasma and serum samples were frozen and stored at $86^{\circ} \mathrm{C}$ for laboratory analysis. The samples were analysed in a national central laboratory in Beijing (medical laboratory accreditation certificate ISO 15189:2007) with strict quality control ${ }^{(39,48,49)}$.

We focused on biomarkers related to Fe status: serum ferritin was assessed by RIA at North Institute of Bio-Tech, China reagents (Gamma counter XH-6020); Hb was measured by volume conductivity light-scatter method with a Beckman Coulter, USA reagents (Beckman Coulter LH750 automated analyzer); and transferrin and soluble transferrin receptor were determined by nephelometry method with a Siemens analyser, Germany reagents (Siemens BNP analyzer). High-sensitivity CRP assessed by immunoturbidimetry with a Denka Seiken analyser, Japan reagents (Hitachi 7600 automated analyzer), was used as an indicator to identify participants with inflammation (CRP $\geq 3 \mathrm{mg} / \mathrm{l})$. According to WHO criteria ${ }^{(4)}$, ID was defined as serum ferritin concentrations $<15 \mathrm{ng} / \mathrm{ml}$, and anaemia was defined as $\mathrm{Hb}$ concentrations $<130 \mathrm{~g} / \mathrm{l}$ for males and $<120 \mathrm{~g} / \mathrm{l}$ for females. Participants with low serum ferritin combined with low $\mathrm{Hb}$ were considered as IDA. Mild anaemia was defined as a $\mathrm{Hb}$ concentration between 100 and $129 \mathrm{~g} / \mathrm{l}$ in males and between 100 and $119 \mathrm{~g} / 1$ in females ${ }^{(40,41)}$.

\section{Other demographic and lifestyle variables}

In our study, we focused on the main dependent variable - that is, Fe status - and the main independent variables - that is, dietary intakes. In addition, we included a number of other demographic and lifestyle variables: the continuous variables age, BMI and physical activity level (PAL) and the categorical variables residence area, highest education level and smoking status. BMI was calculated as weight in kilograms divided by the square of height in metres. Weight was measured using certified scales, with division value $\leq 0 \cdot 1 \mathrm{~kg}$. Measurements were carried out in the early morning and subjects were required to be fasting, hatless, barefoot, wearing only underclothes and to stand quietly in the middle of the scale, with weight of the two legs evenly distributed. The readings were recorded to the nearest $0 \cdot 1 \mathrm{~kg}$. Height was measured using column height gauges, with division value of $0.1 \mathrm{~cm}$. Subjects were required to be hatless, barefoot, with untied hair and stand in attention, with the readings recorded to the nearest $0.1 \mathrm{~cm}$. For PAL, a question addressing 'PAL involved in work' was administered, and the answers were as follows: (1) very light physical activity (working in a sitting position, e.g. office worker, watch repairer, etc.), (2) light physical activity (working in standing position, e.g. salesperson, laboratory technician, teacher, etc.), (3) moderate physical activity (student, driver, electrician, metal worker, etc.), (4) heavy physical activity (farmer, dancer, steel worker, athlete, etc.), (5) very heavy physical activity (loader, logger, miner, stonecutter, etc.). On the basis of the Chinese Dietary Reference Intakes (2000 edition) ${ }^{(50)}$, PAL was quantised into multiples of BMR in our analysis: $1.3 \times$ BMR for very light in both sexes, 1.6 and $1.5 \times$ BMR for light, 1.7 and $1.6 \times$ BMR for moderate, $2 \cdot 1$ and $1.9 \times$ BMR for heavy, 2.4 and $2.2 \times$ BMR for very heavy in males and females, respectively ${ }^{(50)}$. Residence 
area was divided into $1=$ urban and $2=$ rural. Highest education level was classified into low $(1=$ primary school and lower $)$, middle $(2=$ lower middle school, upper middle school and technical or vocational school) and high $(3=$ college, university and higher). Smoking status was also categorised as yes $(1=$ former or current smoker $)$ or no $(0=$ never smoker $)$. Variables with too many missing values such as marital status, family and individual income were not included.

\section{Statistical analysis}

Statistical analyses were conducted using SPSS version 20 for WINDOWS. Ferritin was log transformed (log-ferritin) to address the lack of normality of this variable. In descriptive analyses, mean values and standard deviations were calculated for continuous variables and percentages were calculated for categorical variables. Independent samples $t$ test was used to compare the means of $\mathrm{Fe}$ status biomarkers and dietary $\mathrm{Fe}$ intakes between males and females. The $\chi^{2}$ Test was used for comparison of prevalence rates between males and females. We divided the population into five groups according to quintiles of animal protein intake per $4.2 \mathrm{MJ} / \mathrm{d}$ in males and females, respectively. One-way ANOVA with a test for linear trend was used to compare the means among groups, and when the homogeneity of variance was not satisfied, the JonckheereTerpstra test was used to detect the linear trend among groups. $\chi^{2}$ Tests with a test for linear trend were used to analyse the percentages and linear trends among groups.

Multiple linear regression models were used to investigate the relationship between dietary factors and log-ferritin, and two separate models were created for nutrients or foods both in males and females. The above-mentioned nutrient variables and food group variables were, respectively, included in the 'nutrient model' and the 'food model', whereas the demographic and lifestyle variables were included in each model to control for their potential confounding effects. The 'STEPWISE' method was used to screen variables in each model. For this purpose, both haem Fe and non-haem Fe intakes were included in the nutrient model, and total Fe intake was not included to avoid possible collinearity. Total Fe intake was analysed in an independent partial correlation analysis after controlling for demographic, lifestyle and nutrient variables. $P$ values were two-tailed, and $P<0.05$ was considered to be statistically significant.

\section{Results}

\section{Prevalence rates of iron deficiency and iron-deficiency} anaemia in Chinese adults

We included a total of 5379 subjects with complete data on Fe biochemical indicators, including 2494 males (with 1416 aged 18-50 years and 1078 over the age of 50 years) and 2885 females (with 1730 aged 18-50 years and 1155 over the age of 50 years). The overall prevalence rates of anaemia, ID and IDA in the pooled population aged $\geq 18$ years were $13.3,11.0$ and $4.3 \%$, respectively. The rates of groups classified by age and sex are shown in Fig. 1. Females aged $18-50$ years had the highest rates, whereas males of the same age group had the lowest rates. Rates

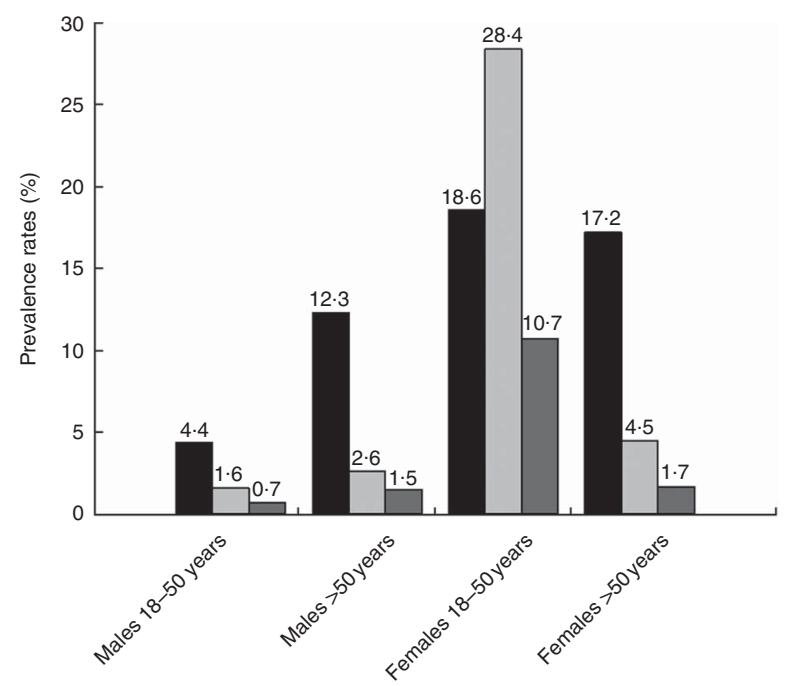

Fig. 1. Prevalence rates of anaemia ( $\square$ ), iron deficiency ( $\square$ ) and iron-deficiency anaemia $(\square)$ in groups classified by age and sex.

of anaemia were similar between the two female groups (females $18-50$ years, $18.6 \% v$. females $>50$ years, $17 \cdot 2 \%$ ); however, rates of ID and IDA were vastly greater in younger females compared with older females (ID: 18-50 year, $28.4 \% v$. $>50$ years, $4.5 \%$; IDA: $18-50$ years, $10 \cdot 7 \% v$. $>50$ years, $1.7 \%$ ).

\section{Dietary iron intake, food sources and iron status}

For the analysis of dietary factors and Fe status, 1360 (46.8\%) males and 1545 (53.2\%) females aged 18-50 years were included in our study. Table 1 presents data on dietary intake and Fe status of males and females. The mean dietary intakes of total Fe in males and females were approximately 23.6 and $20.1 \mathrm{mg} / \mathrm{d}$, respectively, to which haem Fe contributed approximately $4 \%$ $(1.0$ and $0.8 \mathrm{mg} / \mathrm{d}$, respectively) of the total Fe intakes. Males consumed almost double the Chinese recommended nutritional intake (RNI) for Fe (12 mg/d for males), and, on average, Fe consumption of females approximately met the Chinese RNI for Fe $(20 \mathrm{mg} / \mathrm{d} \text { for females })^{(51)}$. The median values of serum ferritin were 123.0 and $26.7 \mu \mathrm{g} / \mathrm{l}$ for males and females, respectively. Compared with females, the log-ferritin and $\mathrm{Hb}$ concentrations in males were much higher, whereas the concentrations of transferrin receptor were significantly lower, which indicated a higher Fe status in males compared with females.

The top ten food sources (cereals, vegetables, red meat, soyabeans, vegetable oil, white meat, algae, eggs, potatoes and miscellaneous beans) of Fe contributed to about $90 \%$ of the total dietary Fe. The ranking of their relative contributions were consistent in both males and females. The largest and second largest sources of $\mathrm{Fe}$ - cereals and vegetables - altogether contributed to about $60 \%$ of the total dietary Fe, followed by red meat and soyabeans, each of which contributed about $7 \%$.

\section{Food pattern and iron status}

The population was divided into five groups according to quintiles of animal protein intakes for males and females 
Table 1. Dietary iron intakes and the top ten main food sources and iron status between males and females aged $18-50$ years

(Mean values and percentages; mean values and standard deviations; median and 25th and 75th percentile)

\begin{tabular}{|c|c|c|c|c|c|}
\hline & \multicolumn{2}{|c|}{ Males } & \multicolumn{2}{|c|}{ Females } & \multirow[b]{2}{*}{$P^{*}$} \\
\hline & Mean $(\mathrm{mg})$ & Contribution (\%) & Mean (mg) & Contribution (\%) & \\
\hline \multicolumn{6}{|l|}{ Food sources of daily $\mathrm{Fe}$ intake } \\
\hline Cereals & $11 \cdot 0$ & $46 \cdot 6$ & $9 \cdot 0$ & 44.7 & $<0.001$ \\
\hline Vegetables & 3.4 & $14 \cdot 2$ & $3 \cdot 0$ & $15 \cdot 0$ & $<0.001$ \\
\hline Red meat $†$ & 1.8 & $7 \cdot 7$ & 1.5 & 7.4 & $<0.001$ \\
\hline Soyabean & 1.6 & $7 \cdot 0$ & 1.4 & $6 \cdot 8$ & 0.002 \\
\hline Vegetable oil & 0.9 & 4.0 & 0.8 & 4.2 & $<0.001$ \\
\hline White meatł & 0.8 & $3 \cdot 3$ & 0.6 & $2 \cdot 9$ & 0.002 \\
\hline Algae & 0.7 & $2 \cdot 8$ & $0 \cdot 6$ & $2 \cdot 9$ & 0.481 \\
\hline Eggs & 0.6 & 2.5 & 0.6 & $2 \cdot 9$ & 0.528 \\
\hline Potatoes & 0.3 & $1 \cdot 2$ & 0.3 & 1.4 & 0.451 \\
\hline \multirow[t]{2}{*}{ Miscellaneous beans } & 0.3 & $1 \cdot 1$ & 0.3 & 1.6 & 0.463 \\
\hline & Mean & SD & Mean & SD & $P$ \\
\hline \multicolumn{6}{|l|}{ Daily Fe intakes (/d) } \\
\hline Total Fe (mg) & $23 \cdot 6$ & $8 \cdot 0$ & $20 \cdot 1$ & $7 \cdot 3$ & $<0.001$ \\
\hline Haem Fe (mg) & 1.0 & $1 \cdot 2$ & 0.8 & 1.0 & $<0.001$ \\
\hline Non-haem Fe (mg) & $22 \cdot 6$ & $7 \cdot 6$ & $19 \cdot 3$ & $7 \cdot 1$ & $<0.001$ \\
\hline Total Fe (mg/4.2 MJß) & $9 \cdot 6$ & 2.5 & $10 \cdot 0$ & $2 \cdot 8$ & $<0.001$ \\
\hline Haem Fe (mg/4.2 MJ) & 0.4 & 0.5 & 0.4 & 0.5 & 0.876 \\
\hline Non-haem Fe (mg/4.2 MJ) & $9 \cdot 2$ & $2 \cdot 3$ & $9 \cdot 6$ & $2 \cdot 6$ & $<0.001$ \\
\hline \multicolumn{6}{|l|}{ Fe status } \\
\hline \multicolumn{6}{|l|}{ Serum ferritin $(\mu \mathrm{g} / \mathrm{l})$} \\
\hline Median & \multirow{2}{*}{\multicolumn{2}{|c|}{$\begin{array}{c}123 \cdot 0 \\
77 \cdot 8,204 \cdot 3\end{array}$}} & \multirow{2}{*}{\multicolumn{2}{|c|}{$\begin{array}{c}26 \cdot 7 \\
13 \cdot 5,48 \cdot 0\end{array}$}} & \\
\hline 25th, 75th percentile & & & & & \\
\hline Log-ferritin & 4.9 & 0.9 & $3 \cdot 2$ & 1.0 & $<0.001$ \\
\hline $\mathrm{Hb}(\mathrm{g} / \mathrm{l})$ & $156 \cdot 0$ & $12 \cdot 6$ & 133.6 & 13.5 & $<0.001$ \\
\hline Transferrin receptor $(\mathrm{mg} / \mathrm{l})$ & 1.3 & 0.4 & 1.5 & 0.5 & $<0.001$ \\
\hline
\end{tabular}

separately. Tables 2 and 3 show the specific dietary and Fe status data among groups.

The dietary characteristics among groups were largely consistent among males and females. Dietary patterns throughout the five groups were consistently predominantly plant-based diets, with plant foods (including cereals, potatoes, miscellaneous beans, vegetables, fruits, algae, soyabeans, nuts and seeds, plant oil and liquor) providing about $70 \cdot 1-92 \cdot 1$ and $68.6-92.5 \%$ of the total energy in males and females, respectively. From group 1 to 5 , animal protein intakes increased about ten times, from $2 \cdot 0$ (sD 1.4) to $20 \cdot 4$ (sD 5.2) g/4.2 MJ per d in males and from 1.9 (SD 1.4) to 21.4 (SD 5.6) $\mathrm{g} / 4.2 \mathrm{MJ}$ per $\mathrm{d}$ in females, with the red meat consumption increased about fourteen to fifteen times and haem Fe consumption increased about twenty times. The group consuming more animal protein in their daily diet tended to consume more red meat, white meat, eggs and dairy products and less cereals, potatoes and miscellaneous beans. Consumption of vegetables and fruits and soyabean and nuts did not show significant differences among groups. Subjects consuming greater quantities of animal foods were significantly more likely to consume tea and coffee. Females consuming more animal foods were significantly more likely to be alcohol consumers. In males, age and BMI did not differ significantly throughout the multiple groups. However, younger females tended to consume more animal protein, and females with higher intake of animal protein had a lower BMI. PAL, the percentages of urban area and education level were significantly higher in groups with more animal protein consumption.

Throughout the five groups, both males and females tended to consume adequate quantities of $\mathrm{Fe}$ as per the RNI. As would be expected, red meat and haem Fe consumption tended to be significantly greater in subjects consuming more animal protein. Yet, there were no differences in Fe status (as defined by logferritin and transferrin receptor) in females and the prevalence rates of ID or IDA in both sexes. Despite this, the Fe status of males (as defined by log-ferritin $(P=0.019)$ and transferrin receptor $(P=0.024))$ was significantly greater in groups consuming greater amounts of animal protein. However, as the intake of animal foods increased, differences in transferrin receptor were in fact very small across the quintiles among males.

\section{Regression and correlation analyses of potential factors with log-ferritin}

Table 4 shows the outcomes of linear regressions for the whole group (1360 males and 1545 females) and the non-anaemic group (1353 males and 1408 females), respectively. Both the 
Table 2. Demographic factors, lifestyle factors, food and nutrient intakes and iron status in each dietary group divided by animal protein intake in males aged $18-50$ years

(Mean values and standard deviations; median and 25th, 75th percentile)

\begin{tabular}{|c|c|c|c|c|c|c|c|c|c|c|c|}
\hline & \multicolumn{10}{|c|}{ Quintiles of animal protein intake per $4.2 \mathrm{MJ} / \mathrm{d}$} & \multirow[b]{3}{*}{$P_{\text {for trend }}$} \\
\hline & \multicolumn{2}{|c|}{$1(n 271)$} & \multicolumn{2}{|c|}{$2(n 274)$} & \multicolumn{2}{|c|}{$3(n 271)$} & \multicolumn{2}{|c|}{$4(n 272)$} & \multicolumn{2}{|c|}{$5(n$ 272) } & \\
\hline & Mean & SD & Mean & SD & Mean & SD & Mean & SD & Mean & SD & \\
\hline \multicolumn{12}{|l|}{ Demographic and lifestyle factors } \\
\hline Age (years) & 37.2 & 8.5 & $37 \cdot 0$ & 8.5 & 37.5 & 8.7 & $37 \cdot 2$ & 8.5 & $36 \cdot 2$ & $9 \cdot 8$ & 0.751 \\
\hline BMI $\left(\mathrm{kg} / \mathrm{m}^{2}\right)$ & $23 \cdot 2$ & $3 \cdot 1$ & $22 \cdot 7$ & $3 \cdot 1$ & $23 \cdot 0$ & $3 \cdot 3$ & $23 \cdot 3$ & $3 \cdot 3$ & 23.0 & $3 \cdot 1$ & 0.790 \\
\hline PAL (×BMR) & 1.9 & 0.3 & 1.9 & 0.3 & 1.8 & 0.3 & $1 \cdot 7$ & 0.3 & $1 \cdot 6$ & 0.3 & $<0.001$ \\
\hline \multicolumn{12}{|l|}{ Residence area } \\
\hline Urban (\%) & \multicolumn{2}{|c|}{$15 \cdot 9$} & \multicolumn{2}{|c|}{$20 \cdot 8$} & \multicolumn{2}{|c|}{$22 \cdot 5$} & \multicolumn{2}{|c|}{39.7} & \multicolumn{2}{|c|}{$50 \cdot 4$} & $<0.001$ \\
\hline \multicolumn{12}{|l|}{ Education level } \\
\hline Low (\%) & \multicolumn{2}{|c|}{$25 \cdot 6$} & \multicolumn{2}{|c|}{$23 \cdot 0$} & 14 & & 14 & & & 96 & $<0.001$ \\
\hline Middle (\%) & 71 & & 72 & & 76 & & 73 & & 76 & 7 & \\
\hline High (\%) & 2 & 9 & 4 & 7 & & 6 & 12 & & 13 & 3.7 & \\
\hline Smoking status & & & & & & & & & & & \\
\hline Former or current (\%) & 80 & & 76 & & 71 & & 68 & & 75 & .7 & 0.039 \\
\hline Daily food intakes (g/4.2 MJ per d) & & & & & & & & & & & \\
\hline Tea consumption (yes, \%) & 29 & & 41 & & 41 & & 44 & & 50 & .7 & $<0.001$ \\
\hline Coffee consumption (yes, \%) & & & 1 & 8 & & 9 & 5 & & & 7.8 & $<0.001$ \\
\hline Alcohol consumption (yes, \%) & 64 & & 61 & & 68 & & 62 & & & .5 & 0.189 \\
\hline $\begin{array}{l}\text { Cereals, potatoes, miscellaneous } \\
\text { beans }\end{array}$ & $200 \cdot 0$ & $37 \cdot 2$ & $179 \cdot 7$ & $35 \cdot 9$ & $166 \cdot 2$ & $30 \cdot 7$ & $153 \cdot 6$ & $33 \cdot 7$ & $138 \cdot 7$ & $34 \cdot 8$ & $<0.001$ \\
\hline Vegetables and fruits & $158 \cdot 8$ & $133 \cdot 1$ & $152 \cdot 2$ & $104 \cdot 8$ & $148 \cdot 5$ & $107 \cdot 5$ & 143.6 & $70 \cdot 4$ & $161 \cdot 7$ & 83.8 & 0.889 \\
\hline Red meat* & 3.6 & 5.4 & $15 \cdot 4$ & 9.4 & 23.3 & $12 \cdot 2$ & 33.1 & $16 \cdot 5$ & 53.9 & $26 \cdot 1$ & $<0.001$ \\
\hline White meat $\dagger$ & $1 \cdot 2$ & 3.8 & $6 \cdot 6$ & $9 \cdot 1$ & $13 \cdot 3$ & $13 \cdot 1$ & $22 \cdot 1$ & 18.4 & $41 \cdot 2$ & $30 \cdot 2$ & $<0.001$ \\
\hline Dairy products & 0.2 & 2.5 & 1.7 & $9 \cdot 3$ & 3.4 & $16 \cdot 2$ & $7 \cdot 2$ & $27 \cdot 0$ & $10 \cdot 0$ & $32 \cdot 7$ & $<0.001$ \\
\hline Eggs & 7.7 & 8.5 & $10 \cdot 4$ & $11 \cdot 3$ & $13 \cdot 3$ & 13.9 & $14 \cdot 0$ & $15 \cdot 2$ & 14.4 & $15 \cdot 5$ & $<0.001$ \\
\hline Soyabeans and nuts & $8 \cdot 4$ & $12 \cdot 9$ & 8.9 & $12 \cdot 1$ & 8.3 & $10 \cdot 3$ & 9.5 & $12 \cdot 8$ & 7.9 & $11 \cdot 1$ & 0.881 \\
\hline Daily nutrient intakes (/d) & & & & & & & & & & & \\
\hline Total energy (kJ) & $10362 \cdot 9$ & $2758 \cdot 1$ & 10628.6 & $2736 \cdot 8$ & $10861 \cdot 2$ & $2681 \cdot 1$ & $10442 \cdot 0$ & $2661 \cdot 4$ & $9661 \cdot 3$ & $2715 \cdot 4$ & 0.002 \\
\hline Plant food (\%TE) & 92.1 & $9 \cdot 1$ & 84.9 & 8.5 & 79.4 & 8.9 & $75 \cdot 6$ & 9.4 & $70 \cdot 1$ & 9.7 & $<0.001$ \\
\hline Protein (\%TE) & $10 \cdot 8$ & $2 \cdot 1$ & $11 \cdot 0$ & 1.8 & 11.5 & $1 \cdot 7$ & $12 \cdot 8$ & $2 \cdot 0$ & $15 \cdot 2$ & $2 \cdot 6$ & $<0.001$ \\
\hline Fat (\%TE) & 24.7 & 9.0 & 29.8 & $9 \cdot 3$ & $32 \cdot 8$ & 8.6 & 34.2 & 8.7 & $35 \cdot 0$ & 9.9 & $<0.001$ \\
\hline $\mathrm{CHO}(\% \mathrm{TE})$ & 65.9 & $9 \cdot 3$ & $60 \cdot 3$ & $9 \cdot 0$ & $56 \cdot 9$ & 8.4 & 53.7 & $9 \cdot 1$ & $50 \cdot 4$ & $9 \cdot 7$ & $<0.001$ \\
\hline Animal protein (g/4.2 MJł) & $2 \cdot 0$ & 1.4 & $5 \cdot 7$ & 0.9 & 8.9 & 1.0 & $12 \cdot 7$ & $1 \cdot 3$ & $20 \cdot 4$ & $5 \cdot 2$ & $<0.001$ \\
\hline Plant protein (g/4.2 MJ) & 23.7 & 5.5 & $20 \cdot 8$ & 4.5 & $18 \cdot 7$ & 4.2 & 18.2 & 4.9 & $16 \cdot 3$ & 4.5 & $<0.001$ \\
\hline Total Fe (mg/4.2 MJ) & 9.5 & $2 \cdot 1$ & $9 \cdot 2$ & $2 \cdot 1$ & $9 \cdot 0$ & $2 \cdot 2$ & $9 \cdot 7$ & $2 \cdot 4$ & $10 \cdot 6$ & $3 \cdot 1$ & $<0.001$ \\
\hline Haem Fe $(\mathrm{mg} / 4.2 \mathrm{MJ})$ & 0.05 & $0 \cdot 10$ & 0.21 & 0.18 & 0.33 & 0.21 & 0.53 & 0.33 & 0.99 & 0.68 & $<0.001$ \\
\hline Non-haem Fe (mg/4.2 MJ) & 9.4 & $2 \cdot 1$ & $9 \cdot 0$ & $2 \cdot 1$ & $8 \cdot 7$ & $2 \cdot 2$ & $9 \cdot 2$ & $2 \cdot 3$ & 9.6 & $2 \cdot 7$ & 0.236 \\
\hline Dietary fibre $(\mathrm{g} / 4.2 \mathrm{MJ})$ & $5 \cdot 8$ & $3 \cdot 8$ & $5 \cdot 2$ & $2 \cdot 0$ & 4.6 & 1.9 & $5 \cdot 1$ & $3 \cdot 1$ & $4 \cdot 7$ & $2 \cdot 3$ & $<0.001$ \\
\hline Ascorbic acid (mg/4.2 MJ) & $36 \cdot 2$ & $21 \cdot 8$ & 33.0 & $20 \cdot 3$ & 33.5 & $20 \cdot 8$ & $35 \cdot 6$ & $19 \cdot 8$ & 39.9 & $26 \cdot 0$ & 0.017 \\
\hline $\mathrm{Ca}(\mathrm{mg} / 4.2 \mathrm{MJ})$ & $161 \cdot 2$ & $87 \cdot 0$ & $161 \cdot 2$ & $69 \cdot 2$ & $158 \cdot 2$ & 74.0 & 173.9 & $71 \cdot 3$ & $196 \cdot 8$ & $81 \cdot 8$ & $<0.001$ \\
\hline Retinol equivalent ( $\mu \mathrm{g} R E / 4 \cdot 2 \mathrm{MJ}$ ) & $127 \cdot 8$ & $120 \cdot 4$ & $162 \cdot 0$ & 157.9 & $163 \cdot 3$ & $131 \cdot 1$ & 209.2 & 203.1 & 298.0 & $320 \cdot 1$ & $<0.001$ \\
\hline $\mathrm{Zn}(\mathrm{mg} / 4 \cdot 2 \mathrm{MJ})$ & 4.5 & 1.3 & 4.6 & 0.8 & 4.7 & 0.7 & $5 \cdot 3$ & 0.9 & $6 \cdot 0$ & $1 \cdot 2$ & $<0.001$ \\
\hline $\mathrm{Mg}(\mathrm{mg} / 4 \cdot 2 \mathrm{MJ})$ & 141.0 & $34 \cdot 1$ & 133.2 & $26 \cdot 9$ & $124 \cdot 6$ & $26 \cdot 8$ & $130 \cdot 0$ & $29 \cdot 4$ & $132 \cdot 6$ & $29 \cdot 2$ & $<0.001$ \\
\hline Fe status & & & & & & & & & & & \\
\hline Serum ferritin $(\mu \mathrm{g} / \mathrm{l})$ & & & & & & & & & & & \\
\hline Median & 110 & & 124 & & 11 & & 129 & & & 8.3 & \\
\hline 25th, 75th percentile & 70.8, & 79.5 & $76 \cdot 8,2$ & $208 \cdot 0$ & 76.3, & $191 \cdot 8$ & $80 \cdot 8,2$ & $20 \cdot 5$ & $80 \cdot 1$ & $228 \cdot 2$ & \\
\hline Log-ferritin & $4 \cdot 8$ & 0.8 & 4.9 & 0.8 & 4.9 & 0.8 & 4.9 & 0.9 & 4.9 & 0.9 & 0.019 \\
\hline Transferrin receptor (mg/l) & 1.3 & 0.5 & 1.4 & 0.5 & 1.3 & 0.5 & $1 \cdot 3$ & 0.4 & $1 \cdot 3$ & 0.4 & 0.024 \\
\hline $\mathrm{Hb}(\mathrm{g} / \mathrm{l})$ & $155 \cdot 2$ & $12 \cdot 1$ & 156.5 & $12 \cdot 9$ & $156 \cdot 0$ & 13.0 & $155 \cdot 8$ & $12 \cdot 0$ & $156 \cdot 1$ & $12 \cdot 7$ & 0.631 \\
\hline Fe deficiency (\%) & & 1 & & $\cdot 1$ & & 1.5 & & 8 & & 1.5 & 0.513 \\
\hline Fe-deficiency anaemia (\%) & & 7 & & 7 & & .4 & & 4 & & 0.4 & 0.735 \\
\hline
\end{tabular}

PAL, physical activity level; TE, total energy; $\mathrm{CHO}$, carbohydrates; $\mathrm{RE}$, retinol equivalents.

${ }^{*}$ Red meat, that is, livestock meat.

† White meat, the sum of poultry and fish flesh.

$\ddagger \mathrm{g} / 4 \cdot 2 \mathrm{MJ}$, that is, $\mathrm{g} / 1000 \mathrm{kcal}$, which is a unit of nutrient/food density used to control for energy intakes.

food and nutrient models were built separately for males and females in each group.

For the whole group, the $R^{2}$ values of food and nutrient models were 8.3 and $6.6 \%$ for males and 1.3 and $1.6 \%$ for females, respectively. Of dietary variables, dietary haem Fe
$(P=0.010)$ was positively associated with log-ferritin in males, and its increase of $1 \mathrm{mg} / 4.2 \mathrm{MJ}$ per $\mathrm{d}$ was accompanied by a $12.3(95 \%$ CI $2.9,21.7) \%$ increase in serum ferritin concentrations, whereas dietary non-haem Fe $(P=0.024)$ was positively associated with log-ferritin in females, and its increase of 
Table 3. Demographic factors, lifestyle factors, food and nutrient intakes, and iron status in each dietary group divided by animal protein intake in females aged $18-50$ years

\begin{tabular}{|c|c|c|c|c|c|c|c|c|c|c|c|}
\hline & \multicolumn{10}{|c|}{ Quintiles of animal protein intake per $4.2 \mathrm{MJ} / \mathrm{d}$} & \multirow[b]{3}{*}{$P_{\text {for trend }}$} \\
\hline & \multicolumn{2}{|c|}{$1(n 309)$} & \multicolumn{2}{|c|}{$2(n 309)$} & \multicolumn{2}{|c|}{$3(n 309)$} & \multicolumn{2}{|c|}{$4(n 309)$} & \multicolumn{2}{|c|}{$5(n 309)$} & \\
\hline & Mean & SD & Mean & SD & Mean & SD & Mean & SD & Mean & SD & \\
\hline \multicolumn{12}{|l|}{ Demographic and lifestyle factors } \\
\hline Age (years) & 38.6 & $8 \cdot 3$ & $38 \cdot 8$ & 8.0 & 37.7 & 8.5 & $37 \cdot 1$ & 8.5 & $36 \cdot 1$ & 8.5 & $<0.001$ \\
\hline BMI $\left(\mathrm{kg} / \mathrm{m}^{2}\right)$ & $22 \cdot 9$ & 3.0 & $23 \cdot 2$ & 3.4 & 22.5 & $3 \cdot 0$ & $22 \cdot 6$ & 3.1 & $22 \cdot 1$ & 3.0 & $<0.001$ \\
\hline PAL (×BMR) & 1.7 & 0.2 & 1.7 & 0.2 & 1.6 & 0.2 & 1.5 & 0.2 & 1.5 & 0.2 & $<0.001$ \\
\hline \multicolumn{12}{|l|}{ Residence area } \\
\hline Urban (\%) & \multirow{2}{*}{\multicolumn{2}{|c|}{$14 \cdot 2$}} & \multicolumn{2}{|c|}{$19 \cdot 1$} & \multicolumn{2}{|c|}{$26 \cdot 2$} & \multicolumn{2}{|c|}{$40 \cdot 5$} & \multicolumn{2}{|c|}{$51 \cdot 8$} & $<0.001$ \\
\hline \multicolumn{10}{|l|}{ Education level } & & \\
\hline Low (\%) & \multicolumn{2}{|c|}{44.0} & \multicolumn{2}{|c|}{$37 \cdot 2$} & & .1 & 20. & & 16 & & $<0.001$ \\
\hline Middle (\%) & & & 58 & & & 0 & $67 \cdot$ & & 71 & & \\
\hline High (\%) & & .7 & & 9 & & 1.9 & 12. & & 11 & & \\
\hline Smoking status & & & & & & & & & & & \\
\hline Former or current (\%) & & 9 & & 5 & & 2.9 & 3. & & & 6 & 0.149 \\
\hline Daily food intakes (g/4.2 MJ per d) & & & & & & & & & & & \\
\hline Tea consumption (yes, \%) & & 9 & 19 & & & .6 & 29. & & 26 & & $<0.001$ \\
\hline Coffee consumption (yes, \%) & & 3 & & 6 & & 1.2 & $8 \cdot$ & & & 1 & $<0.001$ \\
\hline Alcohol consumption (yes, \%) & & 2 & & 8 & & .4 & 12 & & 15 & 9 & $<0.001$ \\
\hline Cereals, potatoes and miscellaneous beans & $199 \cdot 6$ & $39 \cdot 4$ & $177 \cdot 7$ & $36 \cdot 1$ & $164 \cdot 3$ & 34.6 & $148 \cdot 6$ & $31 \cdot 3$ & $134 \cdot 0$ & $35 \cdot 1$ & $<0.001$ \\
\hline Vegetables and fruits & $174 \cdot 3$ & $117 \cdot 3$ & 167.4 & 90.4 & $166 \cdot 7$ & 108.5 & 179.5 & $96 \cdot 9$ & $187 \cdot 6$ & $104 \cdot 4$ & 0.038 \\
\hline Red meat* & 3.7 & 5.8 & $14 \cdot 4$ & $9 \cdot 8$ & $23 \cdot 0$ & $12 \cdot 7$ & 33.6 & $17 \cdot 2$ & $52 \cdot 2$ & 30.5 & $<0.001$ \\
\hline White meat $\dagger$ & 0.9 & 3.3 & 6.5 & 9.6 & 13.9 & 14 & $22 \cdot 3$ & $17 \cdot 8$ & $42 \cdot 1$ & $32 \cdot 7$ & $<0.001$ \\
\hline Dairy products & 0.1 & $2 \cdot 4$ & 0.9 & 5.9 & 4.5 & $15 \cdot 8$ & 9.4 & $29 \cdot 4$ & $20 \cdot 1$ & $48 \cdot 4$ & $<0.001$ \\
\hline Eggs & $7 \cdot 3$ & 8.9 & $12 \cdot 2$ & $12 \cdot 8$ & $13 \cdot 7$ & 14.5 & $16 \cdot 8$ & $16 \cdot 4$ & 21.4 & 24 & $<0.001$ \\
\hline Soyabeans and nuts & $8 \cdot 3$ & $14 \cdot 1$ & $8 \cdot 8$ & 11.7 & 8.6 & $12 \cdot 6$ & $9 \cdot 6$ & $13 \cdot 7$ & $8 \cdot 2$ & 10 & 0.807 \\
\hline Daily nutrient intakes (/d) & & & & & & & & & & & \\
\hline Total energy (kJ) & $8520 \cdot 7$ & $2554 \cdot 3$ & $8900 \cdot 6$ & $2486 \cdot 1$ & $9007 \cdot 7$ & $2468 \cdot 6$ & $8464 \cdot 7$ & 2205 & $7922 \cdot 4$ & $2442 \cdot 2$ & $<0.001$ \\
\hline Plant food (\%TE) & $92 \cdot 5$ & 8.5 & $85 \cdot 0$ & 8.8 & $79 \cdot 5$ & 8.7 & $75 \cdot 1$ & 9.5 & $68 \cdot 6$ & $10 \cdot 5$ & $<0.001$ \\
\hline Protein (\%TE) & $10 \cdot 9$ & $2 \cdot 1$ & $11 \cdot 2$ & $2 \cdot 0$ & 11.8 & $2 \cdot 0$ & $13 \cdot 1$ & $2 \cdot 1$ & $15 \cdot 7$ & $2 \cdot 6$ & $<0.001$ \\
\hline Fat (\%TE) & $25 \cdot 2$ & $10 \cdot 7$ & $30 \cdot 3$ & 9.9 & $33 \cdot 1$ & 9.5 & $35 \cdot 4$ & 8.9 & $35 \cdot 8$ & 9.5 & $<0.001$ \\
\hline $\mathrm{CHO}(\% \mathrm{TE})$ & $66 \cdot 3$ & $10 \cdot 2$ & $60 \cdot 6$ & $9 \cdot 3$ & 57.0 & 8.8 & 53.6 & $8 \cdot 4$ & 50.4 & 9.3 & $<0.001$ \\
\hline Animal protein (g/4.2 MJ‡) & 1.9 & 1.4 & $5 \cdot 7$ & 1 & 9.1 & $1 \cdot 1$ & $13 \cdot 2$ & 1.4 & 21.4 & $5 \cdot 6$ & $<0.001$ \\
\hline Plant protein (g/4.2 MJ) & $24 \cdot 1$ & $5 \cdot 4$ & 21 & 5 & $19 \cdot 3$ & $5 \cdot 2$ & $18 \cdot 2$ & 4.9 & $16 \cdot 6$ & $4 \cdot 3$ & $<0.001$ \\
\hline Total Fe (mg/4.2 MJ) & 10 & $2 \cdot 3$ & 9.4 & $2 \cdot 1$ & 9.4 & $2 \cdot 4$ & 10 & $2 \cdot 9$ & $11 \cdot 2$ & 3.6 & $<0.001$ \\
\hline Haem Fe (mg/4.2 MJ) & 0.05 & 0.09 & $0 \cdot 19$ & $0 \cdot 16$ & 0.34 & 0.22 & 0.53 & 0.4 & 0.99 & 0.7 & $<0.001$ \\
\hline Non-haem Fe (mg/4.2 MJ) & 9.9 & $2 \cdot 3$ & $9 \cdot 2$ & $2 \cdot 1$ & 9 & $2 \cdot 4$ & 9.5 & $2 \cdot 8$ & $10 \cdot 2$ & 3.3 & 0.089 \\
\hline Dietary fibre (g/4.2 MJ) & $6 \cdot 3$ & $2 \cdot 6$ & $5 \cdot 6$ & $2 \cdot 3$ & $5 \cdot 2$ & $2 \cdot 3$ & $5 \cdot 3$ & $2 \cdot 6$ & $5 \cdot 3$ & $2 \cdot 9$ & $<0.001$ \\
\hline Ascorbic acid (mg/4.2 MJ) & $39 \cdot 4$ & 26 & 39.4 & $27 \cdot 6$ & 38.8 & 24 & $43 \cdot 3$ & $25 \cdot 4$ & 430 & $28 \cdot 1$ & 0.006 \\
\hline $\mathrm{Ca}(\mathrm{mg} / 4.2 \mathrm{MJ})$ & $170 \cdot 4$ & $86 \cdot 6$ & 166 & 66.9 & $172 \cdot 3$ & $77 \cdot 7$ & 190 & 81.4 & $222 \cdot 3$ & $111 \cdot 3$ & $<0.001$ \\
\hline Retinol equivalent ( $\mu \mathrm{gRE} / 4 \cdot 2 \mathrm{MJ}$ ) & $134 \cdot 4$ & $128 \cdot 5$ & $169 \cdot 4$ & $147 \cdot 5$ & $183 \cdot 7$ & $158 \cdot 7$ & $238 \cdot 6$ & 235.3 & 365.9 & 465.9 & $<0.001$ \\
\hline $\mathrm{Zn}(\mathrm{mg} / 4 \cdot 2 \mathrm{MJ})$ & 4.5 & 0.7 & 4.7 & 1.3 & 4.8 & 0.8 & $5 \cdot 2$ & 0.9 & $6 \cdot 2$ & 1.2 & $<0.001$ \\
\hline $\mathrm{Mg}(\mathrm{mg} / 4 \cdot 2 \mathrm{MJ})$ & $146 \cdot 8$ & 35 & 135.5 & $31 \cdot 6$ & $132 \cdot 6$ & 31 & 133.4 & $32 \cdot 2$ & 139.6 & $33 \cdot 2$ & 0.005 \\
\hline Fe status & & & & & & & & & & & \\
\hline Serum ferritin $(\mu \mathrm{g} / \mathrm{l})$ & & & & & & & & & & & \\
\hline Median & & 6 & 24 & & & 5.9 & $27 \cdot($ & & 28 & & \\
\hline 25th, 75 th percentile & 13.9 & 45.9 & 12.9, & $47 \cdot 2$ & $13 \cdot 4$ & $50 \cdot 1$ & $13 \cdot 3$ & $+8 \cdot 3$ & 14.4, & $50 \cdot 5$ & \\
\hline Log-ferritin & $3 \cdot 2$ & 1.0 & 3.2 & 1.0 & $3 \cdot 2$ & 1.0 & $3 \cdot 1$ & $1 \cdot 1$ & $3 \cdot 2$ & 1.0 & 0.643 \\
\hline Transferrin receptor $(\mathrm{mg} / \mathrm{l})$ & 1.5 & 0.6 & 1.5 & 0.5 & 1.4 & 0.5 & 1.5 & 0.5 & 1.5 & 0.5 & 0.277 \\
\hline $\mathrm{Hb}(\mathrm{g} / \mathrm{l})$ & $133 \cdot 4$ & $12 \cdot 7$ & 135.4 & $15 \cdot 4$ & $134 \cdot 2$ & $14 \cdot 2$ & 132.4 & $13 \cdot 1$ & $132 \cdot 7$ & 11.5 & 0.078 \\
\hline Fe deficiency (\%) & & & 29 & & & 3.8 & 29 . & & 28 & & 0.721 \\
\hline Fe-deficiency anaemia (\%) & & 0 & & 8 & & .0 & 11. & & & 4 & 0.763 \\
\hline
\end{tabular}

PAL, physical activity level; TE, Total energy.

* Red meat, that is, livestock meat.

$\dagger$ White meat, the sum of poultry and fish flesh.

$\ddagger \mathrm{g} / 4 \cdot 2 \mathrm{MJ}$, that is, $\mathrm{g} / 1000 \mathrm{kcal}$, which is a unit of nutrient/food density used to control for energy intakes.

$1 \mathrm{mg} / 4 \cdot 2 \mathrm{MJ}$ per d was accompanied by a $2 \cdot 2$ (95\% CI $0 \cdot 3$ $4 \cdot 1) \%$ increase in serum ferritin. In males, red meat $(P=0 \cdot 010)$, nuts and seeds $(P=0.001)$ were positively related to log-ferritin, and potatoes $(P<0.001)$ and $\mathrm{Mg}(P=0.033)$ were negatively related to log-ferritin. Being an alcohol consumer was positively associated with log-ferritin both in food models $(P=0 \cdot 011)$ and nutrient models $(P=0.015)$ in females. In the partial analysis, total Fe showed a significant correlation in females $(r=0.058$, $P=0.023)$ but not in males $(P=0.639)$. BMI was positively associated with log-ferritin in both males $(P<0.001)$ and females $(P<0.05)$. Age showed a positive correlation $(P<0.05)$ in females but not in males. 
Table 4. Multiple linear regression models for associations of foods or nutrients and other potential factors with log-ferritin (Linear regression $(B)$ and $95 \%$ confidence intervals)

\begin{tabular}{|c|c|c|c|c|c|c|}
\hline \multirow[b]{2}{*}{ Variables } & \multicolumn{3}{|c|}{ Whole group* } & \multicolumn{3}{|c|}{ Non-anaemic group $\dagger$} \\
\hline & $B \ddagger$ & $95 \% \mathrm{Cl}$ & $P$ & $B$ & $95 \% \mathrm{Cl}$ & $P$ \\
\hline \multicolumn{7}{|l|}{ Food model for males } \\
\hline BMI $\left(\mathrm{kg} / \mathrm{m}^{2}\right)$ & $6 \cdot 7$ & $5 \cdot 3,8 \cdot 1$ & $<0.001$ & $6 \cdot 4$ & $5 \cdot 1,7 \cdot 8$ & $<0.001$ \\
\hline Potatoes (g/4.2 MJ per $d \S)$ & $-1 \cdot 7$ & $-2.5,-0.9$ & $<0.001$ & -1.5 & $-2 \cdot 3,-0.7$ & $<0.001$ \\
\hline Nuts and seeds ( $g / 4.2 \mathrm{MJ}$ per $\mathrm{d})$ & $1 \cdot 4$ & $0.6,2.3$ & 0.001 & 1.3 & $0.5,2 \cdot 1$ & 0.001 \\
\hline Red meat (g/4.2 MJ per dII) & 0.3 & $0.1,0.5$ & 0.010 & & & \\
\hline Poultry (g/4.2 MJ per d) & & & & 0.5 & $0.1,0.8$ & 0.008 \\
\hline Plant oil ( $g / 4.2 \mathrm{MJ}$ per $\mathrm{d})$ & & & & -0.5 & $-0.9,-0.1$ & 0.026 \\
\hline Dairy products (g/4.2 MJ per d) & & & & -0.2 & $-0.4,0.0$ & 0.035 \\
\hline$R^{2}\left(\right.$ adjust $\left.R^{2}\right)$ & & $0.083(0.080)$ & & & $0.088(0.084)$ & \\
\hline \multicolumn{7}{|l|}{ Nutrient model for males } \\
\hline BMI $\left(\mathrm{kg} / \mathrm{m}^{2}\right)$ & $6 \cdot 6$ & $5 \cdot 2,8 \cdot 0$ & $<0.001$ & $6 \cdot 4$ & $5 \cdot 0,7 \cdot 7$ & $<0.001$ \\
\hline Haem Fe (mg/4.2 MJ per d) & $12 \cdot 3$ & $2 \cdot 9,21 \cdot 7$ & 0.010 & $11 \cdot 2$ & $2 \cdot 1,20 \cdot 3$ & 0.016 \\
\hline $\mathrm{Mg}(\mathrm{mg} / 4 \cdot 2 \mathrm{MJ}$ per $\mathrm{d})$ & -0.2 & $-0.3,0.0$ & 0.033 & & & \\
\hline$R^{2}\left(\right.$ adjust $\left.R^{2}\right)$ & & $0.066(0.064)$ & & & $0.063(0.061)$ & \\
\hline \multicolumn{7}{|l|}{ Food model for females } \\
\hline BMI $\left(\mathrm{kg} / \mathrm{m}^{2}\right)$ & 1.8 & $0.1,3.5$ & 0.041 & & & \\
\hline Age (years) & 0.7 & $0.0,1.3$ & 0.041 & 1.2 & $0.7,1.7$ & $<0.001$ \\
\hline Alcohol $(1=$ yes, $0=$ no $)$ & $22 \cdot 1$ & $5 \cdot 0,39 \cdot 2$ & 0.011 & $23 \cdot 3$ & $7 \cdot 5,39 \cdot 0$ & 0.004 \\
\hline$R^{2}$ (adjust $R^{2}$ ) & & $0.013(0.011)$ & & & $0.019(0.018)$ & \\
\hline \multicolumn{7}{|l|}{ Nutrient model for females } \\
\hline BMI $\left(\mathrm{kg} / \mathrm{m}^{2}\right)$ & 1.8 & $0.0,3.5$ & 0.045 & & & \\
\hline Age (years) & 0.7 & $0.0,1.3$ & 0.035 & 1.2 & $0.7,1.7$ & $<0.001$ \\
\hline Alcohol $(1=$ yes, $0=$ no $)$ & $21 \cdot 3$ & $4.2,38.4$ & 0.015 & $23 \cdot 3$ & $7 \cdot 5,39.0$ & 0.004 \\
\hline Non-haem Fe (mg/4.2 MJ per d) & $2 \cdot 2$ & $0.3,4.1$ & 0.024 & & & \\
\hline$R^{2}$ (adjust $R^{2}$ ) & & $0.016(0.014)$ & & & $0.019(0.018)$ & \\
\hline
\end{tabular}

* It includes all subjects aged 18-50 years in our analysis.

$\dagger$ It refers to subjects who were non-anaemic of the whole group.

$\ddagger$ It shows percentage increase in ferritin with 1 unit change in the variable.

$\S \mathrm{g} / 4.2 \mathrm{MJ}$, that is, $\mathrm{g} / 1000 \mathrm{kcal}$, which is a unit of nutrient/food density used to control for energy intakes.

II Red meat, that is, livestock meat.

For the non-anaemic group, outcomes were generally consistent with the whole group, except that poultry $(P=0.008)$, not red meat, in males was positively associated with logferritin, and non-haem Fe did not show any significance in females with log-ferritin. For the partial analysis in this group, total $\mathrm{Fe}$ still showed a marginal significance in females ( $r=0.051, P=0.058)$ but not in males $(P=0.652)$.

\section{Discussion}

Dietary patterns ${ }^{(3,34,35)}$ and Fe status ${ }^{(1,2)}$ differ greatly between developed and developing countries. A number of studies have been undertaken to investigate the relationship of diets and food compositions with Fe status in developed countries with Western diets. The higher prevalence of ID in developing countries was inherently attributed to the higher intakes of plant Fe and its poor bioavailability; however, a few studies have questioned such a relation. Our study investigated Fe status and explored dietary and other potential factors related to it by using nationally sampled data in China. We found that Chinese females, who were 18-50 years old and whose total Fe intakes were about $20 \mathrm{mg} / \mathrm{d}$, consumed diets with haem Fe at extremely different levels, from 0.5 to $8.8 \%$ of total dietary Fe, and had similar levels of ferritin, transferrin receptor and $\mathrm{Hb}$ as well as rates of ID and IDA. We also found a significant correlation of
Fe status with dietary haem Fe only in males with sufficient supply of dietary Fe and good Fe status. These results suggest that there is no definite association of haem Fe intakes with Fe status, and that a predominantly plant-based diet is not necessarily responsible for poor Fe status.

In China, some studies ${ }^{(52,53)}$ have provided national data on the prevalence of anaemia, whereas a few studies have reported data on the epidemiology of ID or IDA according to our literature review. Our study identified that the prevalence rates of ID approximately amounted to two and three times the corresponding rates of IDA, in accordance with the hypothesised relationship between prevalence of ID and IDA proposed in the document of WHO in $2001^{(4)}$. The prevalence of ID in females aged $18-50$ years in China $(28.4 \%)$ was higher compared with developed countries $(5 \cdot 2-13 \cdot 2 \%)^{(54-56)}$, whereas the prevalence in young adult males $(1.6 \%)$ was similar to that in developed countries $(1-2 \%)^{(54-56)}$.

Compared with the median or mean intakes of $\mathrm{Fe}$ $(8.8-13.9 \mathrm{mg} / \mathrm{d})^{(24)}$ among individuals in developed countries, Chinese intake far more dietary Fe $(20.1-23.6 \mathrm{mg} / \mathrm{d})$, and they have a dietary Fe density about $10 \mathrm{mg} / 4.2 \mathrm{MJ}$ per $\mathrm{d}$, exceeding the $7 \mathrm{mg} / 4.2 \mathrm{MJ}$ per $\mathrm{d}$ of a typical Western $\operatorname{diet}^{(57)}$. It seems counter-intuitive that, although the Chinese have higher intakes of total dietary Fe, yet they have higher ID rates, compared with Western countries. Possible explanations are discussed below. 
A study ${ }^{(58)}$ doubted that these dietary Fe intakes calculated on the basis of Chinese Food Composition Table and thought they might have been overestimated. However, results from the Fourth China Total Diet Study ${ }^{(59)}$ estimating the dietary nutrients and contaminants through representative cooked edible foods (the mean intakes for Fe were 22.2 and $19.8 \mathrm{mg} / \mathrm{d}$ in males and females, respectively, aged $20-50$ years, according to measured food Fe content) were consistent with our study and many other reports ${ }^{(52,60)}$. This gives some validation to the methods we used to quantify Fe intakes in this study.

Another explanation for high $\mathrm{Fe}$ intake with high ID prevalence is the quality, instead of the quantity, of dietary Fe. Considering the dietary sources of $\mathrm{Fe}$, vegetables make the second largest contribution in the Chinese diet (14-15\%), which is about two-fold of that in Western diets (8-9\% in UK, $6 \cdot 5-8.8 \%$ in New Zealand $)^{(21,55)}$. Meat and meat products occupied the second position in Western diets (15-21\% in UK, $19 \cdot 0-22 \cdot 1 \%$ in New Zealand) ${ }^{(21,55)}$, about two-fold of that in Chinese diets (10-11\%). In addition, soyabean was also an important source of Fe (approximately $7 \%$ total Fe intake) in the Chinese diet, which is not commonly present in a Westernstyle diet. It is obvious that Fe from animal sources (haem Fe) was limited in the Chinese diet; meanwhile, a large number of plant sources provided more plant $\mathrm{Fe}$, leading to a higher total Fe. Haem Fe was reported to contribute $10-15 \%$ of total Fe in Western populations consuming large amounts of animal food $^{(12)}$, whereas in our study a much smaller proportion of haem ( $4 \%$ ) was detected in both males and females. Owing to this fact, the higher rate of ID in Chinese females, if considered only from an ecological perspective, might be simply attributed to the low bioavailability of plant $\mathrm{Fe}^{(5)}$. However, the present results do not support such an explanation. In our stratified analyses, the prevalence of ID did not reduce as their haem Fe intake increased from 0.5 to $9 \%$ of total dietary $\mathrm{Fe}$, a level approximating to that of Western women. In addition, from the $R^{2}$ values of each multiple linear regression model, the diet can explain a very limited portion of the ferritin variation. This hypothesis of high plant food intakes resulting in poor Fe status also could not explain the fact that Chinese males, whose dietary Fe was mostly from plant foods, have a similar ID rate as Western males.

Animal foods are the richest sources of bioavailable dietary $\mathrm{Fe}^{(61)}$. A latest systematic review ${ }^{(62)}$ has investigated the association between consumption of animal flesh foods and $\mathrm{Fe}$ status among adults in Western countries. Findings from the review were inconsistent, but the overall conclusion was that animal flesh consumption is associated with better Fe status in developed nations, indicated by most of the positive and neutral quality studies. From this perspective, our results differed from that review, and situations were different between sexes. Red meat showed significant positive correlations in males, consistent with most association analysis studies ${ }^{(16,63-65)}$, but not in females. These results were not unprecedented and are consistent with some studies ${ }^{(66,67)}$, which observed higher ferritin concentrations or lower incidence of ID in omnivore males but not females. Moreover, our result showing a lack of relationship between animal flesh intake and Fe status in women of childbearing age was also specifically mentioned in that review $^{(62)}$, which indicated that significant non-dietary factors might be major influencing factors for Fe status compared with diet for the specific sub-group.

We found that haem Fe as well as red meat did not show any benefit on Fe status in females, and several studies in different populations have shown similar findings, including populations in the $\mathrm{UK}^{(21)}$, young Japanese women ${ }^{(22)}$ and healthy Danish men and women ${ }^{(68)}$. Distinctly for females, non-haem Fe was positively related to log-ferritin in our regression analysis. This result contrasts with previous major findings, but it is not unique. A study in rural central Mexico ${ }^{(69)}$ also reported that a better Fe status was associated with greater intakes of foods containing non-haem Fe. The similarities between findings from China and Mexico regarding Fe status and non-haem Fe consumption might reflect an adaptive change in plant $\mathrm{Fe}$ absorption in populations with largely plant-containing diets in developing countries. As the dietary Fe, especially non-haem Fe absorption, was inversely related to body Fe stores ${ }^{(33)}$, nonhaem Fe absorption was up-regulated in participants with low body Fe stores, suggesting that non-haem Fe can contribute more significantly to the amount of total Fe absorbed, because of enhanced bioavailability ${ }^{(29)}$. This might explain why non-haem Fe was more responsive than haem Fe to differences in body Fe status in Chinese females of our study.

As for other dietary factors, alcohol consumption ${ }^{(16,70)}$ was positively and dairy products ${ }^{(71)}$ were negatively associated with log-ferritin in females and males, respectively, consistent with findings from previous studies. $\mathrm{Mg}$ was found to be negatively related to log-ferritin in males, which was inconsistent with previous studies ${ }^{(49,72)}$ finding that serum $\mathrm{Mg}$ or $\mathrm{Mg}$ intakes were positively associated with better $\mathrm{Fe}$ status. The exact mechanism of the association between $\mathrm{Mg}$ and $\mathrm{Fe}$ status is unclear at present. The most frequently mentioned enhancer ascorbic acid and inhibitors $\mathrm{Ca}$, tea and coffee consumption $^{(7,12,14)}$ did not show any significance in our study. From the values of $R^{2}$ of each multiple linear regression model, we can see that the diet explains a very small portion of the ferritin variation, especially in females. Those non-dietary factors not included in our analysis such as menstrual blood flow ${ }^{(22)}$ in females might be more important in influencing factors of Fe status compared with diet.

In the 1990s, the theory that Fe absorption adapted to maintain a set point of individual homoeostasis of $\mathrm{Fe}$ has been raised $^{(73,74)}$. This adaptation was then interpreted as two main aspects: adaptation to the body's Fe status and to the dietary Fe availability over time. One aspect is reflected in the inverse relationship between Fe absorption and Fe stores ${ }^{(29,30)}$. For the other aspect, individuals tend to absorb less Fe with the highbioavailability diet or Fe supplementation and more Fe with the low-bioavailability diet ${ }^{(31,32,75)}$. The underlying origin for the effective adaptive mechanisms for Fe was assumed to prevent both ID and Fe overload for survival ${ }^{(29,30)}$.

This adaptive control of Fe absorption may explain why diet showed little effect on Fe status in our study and why haem Fe was positively related to log-ferritin in males but not in females, which may reflect the differences in metabolic regulation responding to the dietary plant Fe between males and females. Chinese females of childbearing age, who consume large 
quantities of plant foods and required more Fe, might develop great potential of adaptation to low-bioavailability Fe for their high turnover rate of body $\mathrm{Fe}$, and therefore their utilisation of haem and non-haem Fe might be not that different, and the correlation between diet and Fe status may become weakened consequently. On the other hand, the situation is quite different for Chinese males. Males tend to be at greater risk of Fe overload than females and their Fe requirements are relatively low, and thus they are under less stress to adaptively improve the utilisation of non-haem Fe. Therefore, haem Fe utilisation is less regulated by the body $\mathrm{Fe}$ status, and dietary intakes thus are reflected in Fe storage levels in males. Our conjecture is that the adaptation in females might be higher in magnitude than males in Chinese populations, differs from other studies ${ }^{(31,32)}$ and requires further verification.

In spite of the existence of such an adaptive mechanism for regulating $\mathrm{Fe}$ absorption described above, ID is widespread in both developed and developing countries, and the ID rate remains high in women of childbearing age in our study. The obvious assumption may be that the enhanced Fe absorption is not sufficiently effective to prevent ID in those with high physiological Fe requirements and lower Fe intakes ${ }^{(30)}$. However, our findings do not seem to support the assumption of insufficient dietary supply, as Fe storage, even at a very low level, is not associated with dietary Fe, definitely in Chinese females whose Fe intakes were maintained about $20 \mathrm{mg} / \mathrm{d}$, implying other explanations for the higher prevalence of ID with a relatively sufficient Fe intake.

An evolutionary perspective provides a possible explanation. It is known that $\mathrm{Fe}$ is an essential nutrient for both humans and pathogenic microbes, and hypoferraemia, known as the secondary result of an innate immune defense, can restrict essential $\mathrm{Fe}$ to pathogens and inhibit pathogen proliferation ${ }^{(76-78)}$. A variety of evidences indicate that ID protects against infectious diseases and decreases the odds of death from infectious diseases $^{(2)}$. Historically, with the emergence of the Agrarian civilisation in ancient China, increased crowding and poor hygiene in settlements likely increased human infestation ${ }^{(79,80)}$. It is suggested that under a selection pressure of infectious diseases, the ID phenotype survived better ${ }^{(2)}$. ID or IDA then is suggested to be an outcome of successful nutritional adaptation to infectious diseases after a long period (several millennia) of evolution, which may explain the widespread nature of ID around the world ${ }^{(2,81)}$. From this perspective, the differences in Fe status situations between developed and developing countries may be due to unbalanced advances in modern medicine (just begun a few generations ago) ${ }^{(2)}$ leading to variant adaptation pressures to infectious diseases. Although the sanitation in China has improved markedly ${ }^{(82)}$ over the last few decades, there is still a big gap between China and the Western countries. For the higher rates of ID observed in our study, the relationship between environmental health conditions and $\mathrm{Fe}$ homoeostasis need to be further explored. In general, we should take a more comprehensive view of the hazards and possible benefits (i.e. the protective effect against infection) of ID, especially when performing interventions to correct ID.

Our study has some limitations. As exposure (diet) and outcome (Fe status) are measured at the same time, cross-sectional studies are unable to identify causal relationships. The three consecutive 24-h dietary assessment method itself has some limitations (e.g. misreporting). However, the reporting accuracy was thought to be acceptable according to a previous study ${ }^{(83)}$ that evaluated the accuracy of the dietary assessment method used in the same survey. In addition, several important factors were not considered in our study, such as genetic variations ${ }^{(16)}$, information on blood donations ${ }^{(23)}$ and menstruation in females ${ }^{(22)}$. More well-designed studies are required to explore the relationships between these factors and Fe status in Chinese populations.

In conclusion, for Chinese females of childbearing age, dietary non-haem but not haem Fe intake is associated with Fe status in a condition of sufficient total Fe supply. For Chinese males with sufficient supply of dietary Fe and good Fe status, Fe status is related to dietary haem Fe and red meat intakes. The diet has a very limited association with Fe status in Chinese adults, indicating that a predominantly plant-based diet, as per Traditional Chinese dietary patterns, may not be entirely responsible for the poor Fe status of the Chinese population. In order to explain the high prevalence of ID in Chinese females, we need to explore other lifestyle and health factors concurrently.

\section{Acknowledgements}

This study used data from CHNS. The authors thank the National Institute of Nutrition and Food Safety, China Center for Disease Control and Prevention, Carolina Population Center, the University of North Carolina at Chapel Hill, the $\mathrm{NIH}$ (R01-HD30880, DK056350 and R01-HD38700) and the Fogarty International Center, NIH, for financial support for CHNS data collection and analyses of files from 1989 to 2006 and both parties plus the China-Japan Friendship Hospital, Ministry of Health for support for CHNS 2009 and future surveys.

This research received no specific grant from any funding agency or from commercial or not-for-profit sectors.

The authors' contributions are as follows: J. H. carried out data collation and calculation, statistical analysis, manuscript designing and writing. X. S. contributed to data analysis and critical revisions of the manuscript. A. F conducted data collation and advised on statistical analysis. J. S., H. L. and M. G. contributed to the editing of the final version of the manuscript. K. L., the corresponding author, had the primary responsibility for the final content. All the authors read and approved the final version of the manuscript.

The authors declare that there are no conflicts of interest.

\section{References}

1. de Benoist B, McLean E, Egli I, et al. (editors) (2008) Worldwide Prevalence of Anaemia 1993-2005: WHO Global Database on Anaemia. Geneva: WHO.

2. Denic S \& Agarwal MM (2007) Nutritional iron deficiency: an evolutionary perspective. Nutrition 23, 603-614.

3. Hambraeus L (1999) Animal- and plant-food-based diets and iron status: benefits and costs. Proc Nutr Soc 58, 235-242.

4. United Nations Children's Fund, United Nations University \& World Health Organization (2001) Iron Deficiency Anaemia 
Assessment, Prevention and Control: A Guide for Programme Managers. Geneva: WHO.

5. Du S, Zhai F, Wang Y, et al. (2000) Current methods for estimating dietary iron bioavailability do not work in China. J Nutr 130, 193-198.

6. Monsen ER, Hallberg L, Layrisse M, et al. (1978) Estimation of available dietary iron. Am J Clin Nutr 31, 134-141.

7. Hunt JR (2005) Dietary and physiological factors that affect the absorption and bioavailability of iron. Int J Vitam Nutr Res $\mathbf{7 5}$, 375-384.

8. Pretorius B, Schonfeldt HC \& Hall N (2016) Total and haem iron content lean meat cuts and the contribution to the diet. Food Chem 193, 97-101.

9. Ball MJ \& Bartlett MA (1999) Dietary intake and iron status of Australian vegetarian women. Am J Clin Nutr $\mathbf{7 0}$, 353-358.

10. Layrisse M, Martinez-Torres C \& Roche M (1968) Effect of interaction of various foods on iron absorption. Am J Clin Nutr 21, 1175-1183.

11. Martinez-Torres C \& Layrisse M (1971) Iron absorption from veal muscle. Am J Clin Nutr 24, 531-540.

12. Hurrell R \& Egli I (2010) Iron bioavailability and dietary reference values. Am J Clin Nutr 91, 1461S-1467S

13. Fairweather-Tait SJ (2004) Iron nutrition in the UK: getting the balance right. Proc Nutr Soc 63, 519-528.

14. Lim KH, Riddell LJ, Nowson CA, et al. (2013) Iron and zinc nutrition in the economically-developed world: a review. Nutrients 5, 3184-3211.

15. Heath AL, Skeaff CM, Williams S, et al. (2001) The role of blood loss and diet in the aetiology of mild iron deficiency in premenopausal adult New Zealand women. Public Health Nutr 4, 197-206.

16. Cade JE, Moreton JA, O'Hara B, et al. (2005) Diet and genetic factors associated with iron status in middle-aged women. $\mathrm{Am}$ J Clin Nutr 82, 813-820.

17. Harvey LJ, Armah CN, Dainty JR, et al. (2005) Impact of menstrual blood loss and diet on iron deficiency among women in the UK. Br J Nutr 94, 557-564.

18. Davis CD, Malecki EA \& Greger JL (1992) Interactions among dietary manganese, heme iron, and nonheme iron in women. Am J Clin Nutr 56, 926-932.

19. Preziosi P, Hercberg S, Galan P, et al. (1994) Iron status of a healthy French population: factors determining biochemical markers. Ann Nutr Metab 38, 192-202.

20. Fleming DJ, Jacques PF, Dallal GE, et al. (1998) Dietary determinants of iron stores in a free-living elderly population: The Framingham Heart Study. Am J Clin Nutr 67, $722-733$.

21. Geissler C \& Singh M (2011) Iron, meat and health. Nutrients 3, 283-316.

22. Asakura K, Sasaki S, Murakami K, et al. (2009) Iron intake does not significantly correlate with iron deficiency among young Japanese women: a cross-sectional study. Public Health Nutr 12, 1373-1383.

23. Pynaert I, De Bacquer D, Matthys C, et al. (2009) Determinants of ferritin and soluble transferrin receptors as iron status parameters in young adult women. Public Health Nutr 12 , $1775-1782$

24. Beck KL, Conlon CA, Kruger R, et al. (2014) Dietary determinants of and possible solutions to iron deficiency for young women living in industrialized countries: a review. Nutrients 6, 3747-3776

25. Beck KL, Kruger R, Conlon CA, et al. (2013) Suboptimal iron status and associated dietary patterns and practices in premenopausal women living in Auckland, New Zealand. Eur J Nutr 52, 467-476.
26. Cook JD \& Reddy MB (2001) Effect of ascorbic acid intake on nonheme-iron absorption from a complete diet. Am J Clin Nutr 73, 93-98.

27. Reddy MB \& Cook JD (1997) Effect of calcium intake on nonheme-iron absorption from a complete diet. Am J Clin Nutr 65, 1820-1825.

28. Hunt JR, Gallagher SK \& Johnson LK (1994) Effect of ascorbic acid on apparent iron absorption by women with low iron stores. Am J Clin Nutr 59, 1381-1385.

29. Cook JD (1990) Adaptation in iron metabolism. Am J Clin Nutr 51, 301-308.

30. Hallberg L, Hulten L \& Gramatkovski E (1997) Iron absorption from the whole diet in men: how effective is the regulation of iron absorption? Am J Clin Nutr 66, 347-356.

31. Hunt JR \& Roughead ZK (2000) Adaptation of iron absorption in men consuming diets with high or low iron bioavailability. Am I Clin Nutr 71, 94-102.

32. Hunt JR (2003) High-, but not low-bioavailability diets enable substantial control of women's iron absorption in relation to body iron stores, with minimal adaptation within several weeks. Am J Clin Nutr 78, 1168-1177.

33. Hunt JR (2003) Bioavailability of iron, zinc, and other trace minerals from vegetarian diets. Am J Clin Nutr $\mathbf{7 8}$, 633S-6395

34. Hu FB (2002) Dietary pattern analysis: a new direction in nutritional epidemiology. Curr Opin Lipidol 13, 3-9.

35. Zhu Q, Tong Y, Wu T, et al. (2013) Comparison of the hypoglycemic effect of acarbose monotherapy in patients with type 2 diabetes mellitus consuming an Eastern or Western diet: a systematic meta-analysis. Clin Ther 35, 880-899.

36. Food and Agriculture Organization of the United Nations (2009) The State of Food and Agriculture: Livestock in the Balance. Rome: FAO.

37. Zhang B, Zhai FY, Du SF, et al. (2014) The China Health and Nutrition Survey, 1989-2011. Obes Rev 15, Suppl. 1, 2-7.

38. Zhang J, Wang H, Wang Y, et al. (2015) Dietary patterns and their associations with childhood obesity in China. Br J Nutr 113, 1978-1984.

39. Yan S, Li J, Li S, et al. (2012) The expanding burden of cardiometabolic risk in China: the China Health and Nutrition Survey. Obes Rev 13, 810-821.

40. Wilson A, Yu HT, Goodnough LT, et al. (2004) Prevalence and outcomes of anemia in rheumatoid arthritis: a systematic review of the literature. Am J Med 116, Suppl. 7A, 50S-57S.

41. Tettamanti M, Lucca U, Gandini F, et al. (2010) Prevalence, incidence and types of mild anemia in the elderly: the 'Health and Anemia' population-based study. Haematologica 95, 1849-1856.

42. Chinese Center for Disease Control and Prevention (2016) China Health and Nutrition Survey-data collection. http://www. cpc.unc.edu/projects/china/about/design/datacoll (accessed March 2016)

43. National Health and Family Planning Commission of the People's Republic of China (2013) Dietary survey methods part 1: 24-hour recall method. http://www.nhfpc.gov. cn/zwgkzt/yingyang/wsbz.shtml (accessed August 2016) (in Chinese).

44. National Health and Family Planning Commission of the People's Republic of China (2013) Dietary survey methods part 2: weighing method. http://www.nhfpc.gov.cn/zwgkzt/ yingyang/wsbz.shtml (accessed August 2016) (in Chinese).

45. Yang Y (2005) China Food Composition 2004 (Book 2), 1st ed. Beijing: Peking University Medical Press (in Chinese)

46. Yang Y, Wang G \& Pan X (2002) China Food Composition 2002, 1st ed. Beijing: Peking University Medical Press (in Chinese) 
47. Chinese Nutrition Society (2008) Chinese Dietary Guidelines (2007 Edition). Lhasa: Tibet People's Publishing House (in Chinese).

48. Li J, Wang R \& Xiao C (2014) Association between chilli food habits with iron status and insulin resistance in a Chinese population. J Med Food 17, 472-478.

49. Zhan Y, Chen R, Zheng W, et al. (2014) Association between serum magnesium and anemia: China Health and Nutrition Survey. Biol Trace Elem Res 159, 39-45.

50. Chinese Nutrition Society (2000) Chinese Dietary Reference Intakes, 1st ed. Beijing: China Light Industry Press (in Chinese).

51. Chinese Nutrition Society (2014) Chinese Dietary Reference Intakes (2013 Edition). Beijing: Science Press (in Chinese).

52. Ge K, Zhai F \& Yan H (1996) The Third National Nutrition Survey. J Hyg Res 25, 3-15 (in Chinese).

53. Piao J, Lai J, Yin S, et al. (2005) Studies of the anemia status on Chinese population. Acta Nutri Sin 27, 268-271, 275 (in Chinese).

54. Cooper M, Greene-Finestone L, Lowell H, et al. (2012) Iron Sufficiency of Canadians. Ottawa: Ministry of Industry. http:// www.statcan.gc.ca/pub/82-003-x/2012004/article/11742-eng. htm (accessed March 2016).

55. University of Otago \& Ministry of Health (2011) A Focus on Nutrition: Key Findings of the 2008/09 New Zealand Adult Nutrition Survey. Wellington: Ministry of Health. http://www. health.govt.nz/publication/focus-nutrition-key-findings-200809-nz-adult-nutrition-survey (accessed March 2016).

56. US Centers for Disease Control and Prevention (2012) Second National Report on Biochemical Indicators of Diet and Nutrition in the US Population 2012. Atlanta, GA: National Center for Environmental Health. http://www.cdc.gov/ nutritionreport/ (accessed March 2016).

57. Carpenter CE \& Mahoney AW (1992) Contributions of heme and nonheme iron to human nutrition. Crit Rev Food Sci Nutr 31, 333-367.

58. Jiang T, Wang Z, Song C, et al. (2014) Analysis of dietary iron intakes of pregnant and lactating women based on food composition databases from China and US. J Hyg Res $\mathbf{4 3}$, 562-566 (in Chinese).

59. Wu Y \& Li X (2015) The Fourth China Total Diet Study. Beijing: Chemical Industry Press (in Chinese).

60. Zeng X (2006) Analysis on the present situation and the causes of the residents' shortage of iron in China. Food Nutr China 12, 55-57 (in Chinese).

61. Sharma S, Sheehy T \& Kolonel LN (2013) Contribution of meat to vitamin $\mathrm{B}(1)(2)$, iron and zinc intakes in five ethnic groups in the USA: implications for developing food-based dietary guidelines. J Hum Nutr Diet 26, 156-168.

62. Jackson J, Williams R, McEvoy M, et al. (2016) Is higher consumption of animal flesh foods associated with better iron status among adults in developed countries? A systematic review. Nutrients $\mathbf{8}, 89$.

63. Leonard AJ, Chalmers KA, Collins CE, et al. (2014) The effect of nutrition knowledge and dietary iron intake on iron status in young women. Appetite 81, 225-231.

64. Blanco-Rojo R, Toxqui L, Lopez-Parra AM, et al. (2014) Influence of diet, menstruation and genetic factors on iron status: a cross-sectional study in Spanish women of childbearing age. Int J Mol Sci 15, 4077-4087.
65. Rigas AS, Sorensen CJ, Pedersen OB, et al. (2014) Predictors of iron levels in 14,737 Danish blood donors: results from the Danish Blood Donor Study. Transfusion 54, 789-796.

66. Haddad EH, Berk LS, Kettering JD, et al. (1999) Dietary intake and biochemical, hematologic, and immune status of vegans compared with nonvegetarians. Am J Clin Nutr 70, 586S-593S.

67. Alexander D, Ball MJ \& Mann J (1994) Nutrient intake and haematological status of vegetarians and age-sex matched omnivores. Eur J Clin Nutr 48, 538-546.

68. Milman N, Pedersen AN, Ovesen L, et al. (2004) Iron status in 358 apparently healthy 80 -year-old Danish men and women: relation to food composition and dietary and supplemental iron intake. Ann Hematol 83, 423-429.

69. Backstrand JR, Allen LH, Black AK, et al. (2002) Diet and iron status of nonpregnant women in rural Central Mexico. Am J Clin Nutr 76, 156-164.

70. Whitfield JB, Zhu G, Heath AC, et al. (2001) Effects of alcohol consumption on indices of iron stores and of iron stores on alcohol intake markers. Alcohol Clin Exp Res 25, 1037-1045.

71. Galan P, Yoon HC, Preziosi P, et al. (1998) Determining factors in the iron status of adult women in the SU.VI.MAX study. SUpplementation en VItamines et Mineraux AntioXydants. Eur J Clin Nutr 52, 383-388.

72. Shi Z, Hu X, He K, et al. (2008) Joint association of magnesium and iron intake with anemia among Chinese adults. Nutrition 24, 977-984.

73. Gavin MW, McCarthy DM \& Garry PJ (1994) Evidence that iron stores regulate iron absorption - a setpoint theory. $A m \mathrm{~J}$ Clin Nutr 59, 1376-1380.

74. Sayers MH, English G \& Finch C (1994) Capacity of the store-regulator in maintaining iron balance. Am J Hematol 47, 194-197.

75. Roughead ZK \& Hunt JR (2000) Adaptation in iron absorption: iron supplementation reduces nonheme-iron but not hemeiron absorption from food. Am J Clin Nutr 72, 982-989.

76. Nairz M, Haschka D, Demetz E, et al. (2014) Iron at the interface of immunity and infection. Front Pharmacol 5, 152 .

77. Cassat JE \& Skaar EP (2013) Iron in infection and immunity. Cell Host Microbe 13, 509-519.

78. Pieracci FM \& Barie PS (2005) Iron and the risk of infection. Surg Infect (Larchmt) 6, Suppl. 1, S41-S46.

79. Kersulyte D, Mukhopadhyay AK, Velapatino B, et al. (2000) Differences in genotypes of Helicobacter pylori from different human populations. J Bacteriol 182, 3210-3218.

80. Goncalves ML, Araujo A \& Ferreira LF (2003) Human intestinal parasites in the past: new findings and a review. Mem Inst Oswaldo Cruz 98, Suppl. 1, 103-118.

81. Wander K, Shell-Duncan B \& McDade TW (2009) Evaluation of iron deficiency as a nutritional adaptation to infectious disease: an evolutionary medicine perspective. Am J Hum Biol 21, 172-179.

82. Li X, Gao Y, Miao Y, et al. (2014) Understanding determinants of inequality in sanitation improvement in rural China. Iran J Public Health 43, 1148-1149.

83. Zhai F, Barry MP, Ma L, et al. (1996) The evaluation of the 24-hour individual dietary recall method in China. J Hyg Res 25, 51-56 (in Chinese). 